\title{
Dehiscence syndrome superior semicircular canal: a case of dehiscence syndrome of the superior semicircular
}

\begin{abstract}
The superior semicircular dehiscence syndrome is a pathology Described in 1998 by Minor et al. Which presents several sound induced vertigo symptoms Included, hearing loss and autophony due to bone dehiscense de este semicircular canal. The diagnosis was based on clinical and confirmation is given by temporal bone CT the. Treatment is surgical repair of expectant or continuity if the clinic is disabling. In This paper we present a case of auditory and vestibular DCSS With symptoms in issuing the phoneme "mmm".
\end{abstract}

Keywords: superior semicircular canal, dehiscence, tullio phenomenon
Volume 6 Issue 6 - 2017

\author{
Victor Mercado M, Francisca Fernández A, \\ Claudia Hernandez B, Carlos Pino U, Ignacio \\ Novoa C, Pablo Herrera C \\ Medical Technologist Mention Otorhinolaryngology, Chile
}

Correspondence: Victor Mercado M, Medical Technologist Mention Otorhinolaryngology, Libertad \# 1348, 6th floor, Chile, Email carlospinou@gmail.com

Received: August 19,2016 | Published: April 17,2017

\section{Summary}

Dehiscence syndrome superior semicircular canal (DCSS) is a condition described in 1998 by Minor et al, presents various symptoms including dizziness induced by sound, hearing loss and autophony by the lack of bone coverage on that channel. Diagnosis is based on clinical and confirmation is obtained by computed tomography crag. The treatment is expectant or surgical repair of continuity if the clinic is incapacitating. In this article a case of DCSS with hearing and vestibular issuing the phoneme "mmm" symptoms occur.

\section{Introduction}

DCSS syndrome is the presence of a solution of continuity between the apex of the superior semicircular canal (CSS) and cerebral fossa media. ${ }^{1}$ Minor et al., ${ }^{2}$ were the first to identify this syndrome in 1998, and is characterized by the presence of vertigo and nystagmus front sounds, pressure changes in the middle ear and / or intracranial pressure. In addition symptoms such as autophony, instability, oscilloscopy and hyperacusis they may occur. Minor argued that the failure of bone coverage or dehiscence act as a "third window" moving at the level of the inner ear in addition to the oval and round windows form, allowing the transmission of vibration to the vestibular apparatus, producing the sensation of vertigo. ${ }^{2}$ The mechanism involved in syndrome DCSS would movement blister channel due to increased endolymphatic complacency, dehiscencia ${ }^{3}$ generated by the system.

A study studying thousand prevalencia4 hue-sos temporary appreciated one DCSS in $0.5 \%$ of cases, the bony plate that covered the CSS was less than $0.1 \mathrm{~mm} 2$ at $1.4 \%$. No local changes were found in the temporal bone that give explain pu-bone erosion, and none of these patients had a prior history of head trauma. This dehiscence was bilateral in most patients, so it is suggested that some embryonic alteration might explain these hallaz-gos, and probably some later event, such as trauma or increased intracranial pressure, could accentuate this condition, de-finishing appearance síntomas. ${ }^{4}$

Initial experiments by Tullio $^{5}$ and subsequently Huizinga \& Euren $^{6,7}$ Demostra-rum fenestration semicircular canals in pigeons, eye and head movements caused by sound evoked in the same plane channel, denominating Tullio phenomenon. Initial clinical studies identified this faith-phe- in patients with syphilis congenital. ${ }^{8}$ However, these findings were subsequently demonstrated in conditions such as deafness congé-nita ${ }^{9}$ of Ménière ${ }^{10}$ syndrome, perilinfática ${ }^{11}$ fistula, trauma encefalocraneano ${ }^{12}$ of Lyme $^{13}$ disease and chronic otitis media with cholesteatoma semicircular ${ }^{14}$ channel erosion.

In similar pathological conditions that can result Tullio phenomenon, the pressure in the ear canal (CAE) with the with-next movement of the tympanic membrane, produces symptoms and signs vestibulares. ${ }^{15}$ This phenomenon was demonstrated in a study carrieddo with chinchillas by Hirvonen et al, who investigated the changes of discharge afferents vestibular in response to changes in the CAE before and after fenestration CSS, and post reparación. ${ }^{16}$ This relationship between the plane and the directional characteristics of the known eye movements evoked both the excitation or inhibition of CSS will help define the pathophysiological characteristics of patients. Then appears, a ver-tico-rotary nystagmus following the plane of the CSS affected, counterclockwise in the case of CSS right and clockwise in the CSS izquierdo. ${ }^{17}$ The con-confirmation by computed tomography (CT) crag high resolution should rea-Lizar with cuts of at least 0.5 $\mathrm{mm}$ and Recon-ing in the plane channel to minimize the number of false positives. ${ }^{18}$ Another useful supplementary examination for the diagnosis of this table is vestibular myogenic evoked potentials (VEMP). With an increase in amplitude and a lower threshold to evoke the potenciales. ${ }^{19}$ Halmagyi et al evaluated the OCU-lar movements in response to low-frequency clicks in patients and healthy control group DCSS. The carrier group had a ten times greater than that observed in healthy subjects answer, therefore present this technique as a valid alternative to DCSS research in patients with dizziness and/ or disequilibrium. ${ }^{20}$

\section{Clinical case}

Male patient 33years old, administrative mining. Browse box two years of evolution characterized by hearing loss and tinnitus pulsatile autophony left ear. In the past eight months imbalance and vertigo goal by issuing the phoneme " $\mathrm{mmm}$ " is added. The review highlights otoscopia standard; Weber test lateralized to the left ear. Audiometry, hearing loss presents driving left ear upward curve and a gap of $40 \mathrm{~dB}$ $(125-250-500 \mathrm{~Hz})$, bone conduction -10dB (Figure 1). With clinical and audiological suspected DCSS VEMP is requested stimulus Burst 
$500 \mathrm{~Hz}$, which has a threshold of p13 waves and n 23 to $65 \mathrm{~dB} \mathrm{nHL}$ and asymmetry in the amplitudes of the p13 waves and $\mathrm{n} 23$ to $90 \mathrm{~dB}$ NHL (Figure 2).

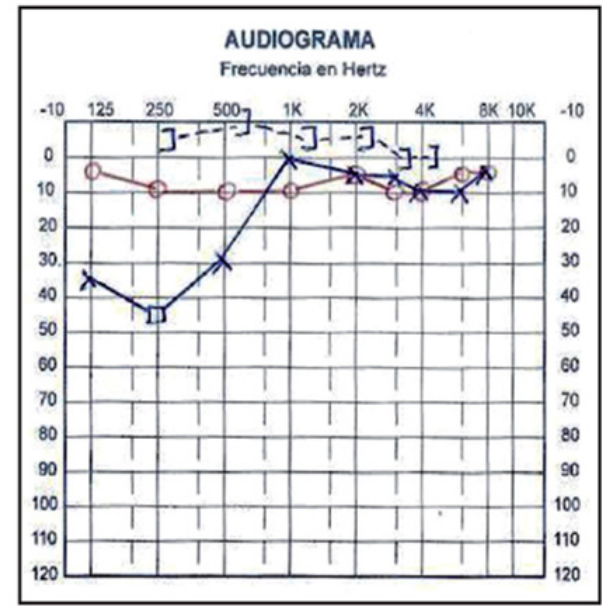

Figure I Conductive hearing loss left ear, rising. And GAP $40 \mathrm{~dB}$., Bone conduction $-10 \mathrm{~dB}$



Figure 2 Asymmetry in the amplitude responses, response threshold abnormally reduced left ear. Compatible with left vestibular pathology.



Figure 3 Spontaneous nystagmus is studied, and the patient is asked to issue phoneme "mmm" horizonto emergence of left-rotatory nystagmus seen in all positions of gaze.

Description of the acquisition: A Toshiba Aquilion 64, Yokohama, Japan. Acquisition of $0.5 \mathrm{~mm} \times 64$. $120 \mathrm{Kv}$. $300 \mathrm{mAs}$. Matrix of $5 \mathrm{I} 2 \times 5 \mathrm{I}$. FOV of $240 \mathrm{~mm}$. Reconstruction of I mm every $0.8 \mathrm{~mm}$ with Bone algorithm. Time of Rotation $0.6 \mathrm{sec}$.
The video presents ausen-cia oculonistagmografía spontaneous nystagmus. The patient is asked to perform phoneme "mmm" observed appearance of horizonto-rotary nystagmus in all positions look, clockwise (Figure 3). A significant caloric testing left vestibular hyperreflexia seen as parameter.

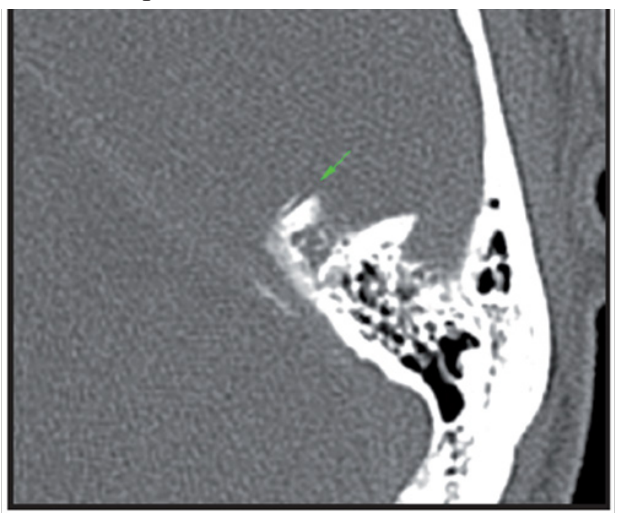

Figure 4a Reconstrucciónn MPR oblique parallel to the plane of the tympanic tegmen. Level window 600 and window width UH 2500 UH. The green arrow indicates the CSCS lacking its superior bony wall.

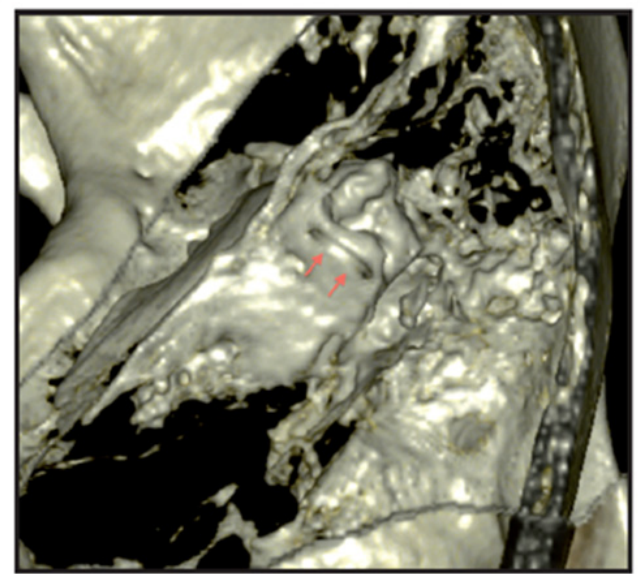

Figure 4b Rendering reconstruction volume highlighting the defect adjacent to the upper wall of CSCS, shown by arrows 4c rojas. Figure bone surface. MPR oblique parallel to the plane of the CSCS which highlights the ósea. VCL wall dehiscence. With the clinical suspicion of DCSS syndrome in left ear temporal bone CT is performed, with cuts of $0.5 \mathrm{~mm}$, which confirms the clinical diagnosis.

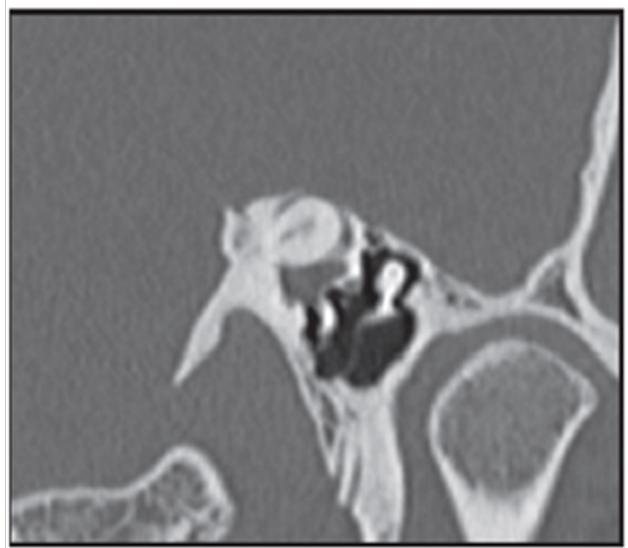

Figure 4c MPR oblicuo paralelo al plano del CSCS donde destaca la dehiscencia de la pared ósea. 


\section{Conclusion}

The DCSS is a relatively new entity. Most publications give few details of symptoms, mainly mentioning imbalance, vertigo or oscilloscopy noise-induced pressure or maneuvers. In a series reported by Kaski, ${ }^{21}$ reports that $89 \%$ of patients had imbalance, oscilloscopy or dizziness in the presence of intense external sounds of sudden onset, such as telephone, traffic noise, cry baby, cry or dental strawberry, expanding clinical presentation of DCSS. A third of them had Tullio phenomenon with his own voice when speaking or making buzz. Changes in intracranial pressure by coughing, nose blowing, flying, causing symptoms in $25 \%$ of subjects. In addition, patients often reported hearing unusual phenomena related to body sounds as heard his footsteps, his muscles when chewing or eye movements. Pulsatile tinnitus was a frequent complaint. It is important to consider the vertigo that occurs in the dental office, and the differential diagnosis between benign paroxysmal positional vertigo (BPPV) and DCSS, as they will be triggered differently. The intensity of the sound generated by the turbine reaches the inner ear by bone conduction, it is transmitted by solid media, such as the skull, with enormous efficiency and maximum speed. However, when it reaches the ear of a patient with DCSS Tullio phenomenon it occurs because above $95 \mathrm{~dB}$ SPL to trigger a precise rotational vertigo. All these inconveniences previously mentioned are caused by low frequency sounds $(0.5-2 \mathrm{kHz})$. The patient reported, particularly referring symptoms when issuing the phoneme "mmm" which generates pressure changes as well as a retro reflected resonance, because the phonatory tube with a frequency of about $110 \mathrm{~Hz}$ is partially occluded, but includes harmonics and other complex frequencies noise. Given the nature of the problem, look for abnormal eye movements against exposure to sound stimuli, inducing positive pressure and/or negative in the CAE during impedance or performing Valsalva maneuver against glottis open and closed glottis. Increased intracranial pressure with the Valsalva maneuver and closed glottis, is transmitted in the CSS, through the meninges and the perilymph of the aqueduct coclear, ${ }^{21}$ generating eye movements in the same plane but opposite direction (ampulípeta) to the observed during the loud noise. Pathophysiologically the "third window" causes a lowfrequency conductive hearing loss is accompanied by thresholds via bone normal or even lower than $0 \mathrm{~dB}$, with a normal acoustic reflex, allowing us to exclude the otosclerosis as a differential diagnosis. Bone conduction humans is less efficient than air conduction, however, the presence of a DCSS generate a vibration of the skull that may cause the oscillation of the dura over the defect, leading to the creation of standing waves and amplification sound, which is transmitted directly to the inner ear fluids with little attenuation, causing stimulation of hair cells in the cochlea at the appropriate frequencies. This explains the symptoms of tinnitus and pulsatile ${ }^{22}$ autophony.

The VEMP is an objective test that evaluates the generation disynaptic vestibulo-cervi-cal. This determines the function of the saccule, posterior labyrinth and inferior vestibular nerve principalmente..$^{23,24}$ It is thought that the ori-page VEMP by stimulation saccule because the latter forms the vestibular organ terminal more sensitive to sound, to be close to the look-tana oval. The large intensity of motion of the perilymph produce greater stimulation of saccular receptors. Furthermore, most neurons sensitive vestibular nerve clicks, which would meet inclinations are in the saccular macula and there is diri-gene by afferents vestibular nerve to the lateral and inferior ${ }^{25}$ vestibular nucleus. Thus, an auditory stimulus type click brief high intensity will produce an ipsilateral inhibitory potential of high amplitude and short latency in the sternocleidomastoid muscle when it is find tonically contracted and exci-rio in the contralateral muscle. This muscle response will be represented as a wave with a positive peak at $13 \mathrm{~ms}$ after a negative and the $23 \mathrm{~ms}$ after stimulation peak. In normal subjects the VEMPs has a threshold usually 90-95dB. In patients with DCSS, the threshold is about $20 \mathrm{~dB}$ lower than the normal subjects and breadth usual level of stimulation of $100-105 \mathrm{~dB}$ can be mind-abnormally high ( $>300$ microvolts). Patients with DCSS also have a lobby oculomotor reflex evoked by click abnormally intense and bajo ${ }^{26,27}$ threshold.

There is a notable difference between the impact-cia radiological and anatomical. While in post mortem studies in temporal bones an incidence of $0.5 \% 4$ was found, in contrast with the results obtained by $\mathrm{CT}$, ranging from $1 \%$ to $17 \% .^{28,29}$ This may be because the resolution of CT not sufficient for bone near deli-very fino; ${ }^{30}$ the orientation of the cuts can increase the number of false positives ${ }^{31}$ and positioning the patient's head varies with each study and therefore there is no standardized variable.

Cloutier $^{32}$ proposed holding TC with re-construction in the plane of committed channel (Pöschl), reducing the prevalence of radiological DCSS $10 \%$ to $4 \%$ with coronal reconstructions. However even diagnosis is made on this box.

The initial treatment of this disease should be conservative, avoiding the patient, the actions that trigger the clínica. ${ }^{2}$ If this behavior is not sufficient or the symptoms are disabling it may refer the patient a resolution quirúrgica, ${ }^{3}$ consisting of closing the communication between the channel and the floor of the middle fossa, showing a clear improvement of vestibular symptoms and disappearance of Tullio phenom-enon. The routes proposed for the closure of the fistula are transmastoid or through middle cranial fossa. Once identified dehiscence, it is sealed with bone wax or a bone graft could be added temporal ${ }^{33}$ muscle fascia. Other alternatives such as fascia, fibrin glue, bone graft and hydroxyapatite cement have also been used in the repair of the defect, with 60. Dehiscence syndrome SEMICIRCULAR SUPERIOR CANAL. A CASE REPORT - V Market, F Fernandez Hernandez C, C Pino, I Novoa, P Herrera various results. ${ }^{1}$ There is initially described by Silverstein ${ }^{34}$ innovative approach, who sugi-gested that dampen the sensitivity of the inner ear by strengthening the oval and round window with fascia may relieve symptoms in some patients, reducing complications Aque-Llos more invasive approaches, via transcranial. twenty-four patients centers who opted for the minimally invasive approach by strengthening the oval window and / or round were studied. The analysis revealed a STAT-cally significant improvement in almost all symptoms except for hearing loss.

Finally, this clinical entity has a high rate of false positives and a variety of clinical presentations therefore we must consider in detail the diagnos-cos differential and supported by complementary examinations get raise this diagnosis with certainty and define the best patient treatment for those carriers DCSS.

\section{Acknowledgments}

None.

\section{Conflicts of interest}

Author declares there are no conflicts of interest.

\section{Funding}

None. 


\section{References}

1. Gianoli GJ. Deficiency of the superior semicircular canal. Curr Opin Otolaryngol Head and Neck Surg. 2001;9(5):336-341.

2. Minor LB, Solomon D, Zinreich JS, et al. Sound- and / or Pressureinduced vertigo due to bone dehiscence of the superior semicircular canal. Arch Otolaryngol Head Neck Surg. 1998;124(3):249-258.

3. Caro J, Fernandez F. Syndrome superior semicircular canal dehiscence: Review. Rev Cir Otorrinolaringol Head Neck. 2006; 66:119-125.

4. Carey JR, Minor LB, Nager GT. Dehiscence and thinning of bone overlying the superior semicircular canal in a temporal bone survey. Arch Otolaryngol Head Neck Surg. 2000;126(2):137-147.

5. Tullio P Das. Ohr und die Entstehung der Sprache und Schrift. Berlin, Germany Urban \& Schwarzenberg, Germany. 1929.

6. Huizinga E. On the sound reactions of Tullio Acta Oto-Laryngologica (Stockh). 1935;22(3):359-369.

7. Eunen AJH, HC Huizinga, Huizinga E, et al. Reaktion mit der Funktion in Zusammenhang des Mittelohres. Acta Otolaryngol (Stockh). 1943;31(3-4):265-339.

8. Mayer JS Fraser. Pathological Changes in the ear in late congenital syphilis. J Laryngol Otol. 1936;51(11):683-714.

9. Kwee SL. The occurrence of the Tullio phenomenon in congenitally deaf children. J Laryngol Otol. 1976;90:501-507.

10. SK Kacker, Hinchcliffe R. Unusual Tullio phenomena. J Laryngol Otol. 1970;84(2): 155-66.

11. EJ Fox, Balkany TJ, Arenberg IK. The Tullio phenomenon and perilymph fistula. Otolaryngol Head Neck Surg. 1988;98(1):88-89.

12. Rottach KG, von Maydell RD, DiScenna AO, et al. Quantitative measurements of eye movements in a patient With Tullio phenomenon. $J$ Vestib Res. 1996;6(4):255-259.

13. Nields JA Kveton JF. Tullio Lyme borreliosis phenomenon and seronegative. Lancet. 1991;338(8759):128-129.

14. Ishizaki H, Pyykko I, Aalto HJ. Tullio Starck phenomenon and postural stability: experimental study in Patients With Normal subjects and dizziness. Ann Otol Rhinol Laryngol . 1971;100(12):976-983.

15. Hennebert C.A new syndrome in hereditary syphilis of the labyrinth. Presse Med Brux Belg. 1911;63:467.

16. TP Hirvonen, JP Carey, CJ Liang, et al. Top canal dehiscence: Mechanisms of pressure sensitivity in a chinchilla model. Arch Otolaryngol Head Neck Surg. 2001;127:1331-1336.

17. KB Sung, Lee TK, Furman JM. Abnormal eye movements in dizzy Patients. Neurol Clin. 2005;23(3):675-703.

18. Williamson RA, Vrabec JT, Coker NJ, et al. Coronal scan prevalence of superior semicircular canal dehiscence. Otolaryngol Head Neck Surg. 2003;129:481-489.
19. Welgampola MS, Colebatch JG. Characteristics and clinical application of vestibular evoked myogenic-potencials. Neurology. 2005;64:1682-1688.

20. Halmagyi GM, McGarvie LA, Yavor RA, et al. The click-ocular reflex evoked lobby semicircular canal dehiscence in top. Neurology. 2003;60(7):1172-1175.

21. Kaski D, Davies R, Luxon L, et al. The Tullio phenomenon: a neglected neurologically presentation. J Neurol. 2012;259(1):4-21.

22. Tilikete C, Krolak-Salmon P, Truy E, et al. Press synchronous oscillations eye bone superior canal dehiscence revealing. Ann Neurol. 2004;56:556-560.

23. Colebatch JG, Halmagyi GM, Skuse NF. Myogenic potentials generated by click-evoked reflex vestibulocollic. J Neurol Neurosurg Psychiatry. 1994;57(2):190-197.

24. SR Watson, Halmagyi GM, Colebatch JG. Vestibular hypersensivity to sound (Tullio phenomenon): structural and functional assessment. Neurology. 2000;54(3):722-728.

25. Halmagyi GM, Curtíos IS. Otolithic function tests. Rev Med Univ Navarra. 2004;47:29-37.

26. Halmagyi GM, McGarvie LA, ST Aw, et al. The clickevoked vestibuloocular reflex dehiscence in superior semicircular canal. Neurology. 2003;60(7):1172-1175.

27. Halmagyi GM, Aw ST, McGarvie LA, et al. Top semicircular canal dehiscence simulating otosclerosis. $J$ Laryngol Otol. 2003;117(7):553-537.

28. Krombach GA, Di Martino E, Schmitz-Rode T, et al. posterior semicircular canal dehiscence: a morphologic cause of Similar giddiness superior semicircular canal dehiscence to. Eur Radiol. 2003;13(6):1444-1450.

29. Piton J, Négrevergne M, Portmann D. Dehiscence of the superior semicircular canal: CT scan approach and classifications. Rev Laryngol Otol Rhinol. 2008;129(1):17-26.

30. Whyte J, Martinez C, Cisneros A. Undone the superior semicircular canal: anatomical study of incidence. Rev Cir Otorrinolaringol Head Neck. 2011;71:39-43.

31. Belden CJ, Weg N, Minor LB. CT evaluation of bone dehiscence of the superior semicircular canal as a cause of sound and / or pressure-induced giddiness. Radiology. 2003;226(2):337-343.

32. Superior I .semicircular canal dehiscence: positive predictive value of high-resolution CT scanning. Eur Arch Otorhinolaryngol. 2008;265(12):1455-1460.

33. Whyte Orozco, Cisneros Gimeno AI, Basurko Aboitz, et al. Torreguitart dehiscence syndrome superior semicircular canal. embryological and surgical aspects. Acta Otorrinolaringol Esp. 2005;56:6-11.

34. Silverstein H, Kartush JM, Parnes LS, et al. MJ Levenson. Round window reinforcement for superior semicircular canal dehiscence: A retrospective multi-center case series. Am J Otolaryngol. 2014;35(3):286-293. 